\title{
NAUDOJAMŲ KLUBO SĄNARIO IMPLANTŲ IŠLIKIMAS BEI PASISKIRSTYMAS PAGAL FIKSACIJOS KAULE PRINCIPĄ TARP SKIRTINGO AMŽIAUS PACIENTŲ GRUPIŲ
}

\author{
Algimantas Čebatorius ${ }^{1,4}$, Aleksej Lebedev ${ }^{1}$, Justinas Stučinskas², Donatas Senkanec ${ }^{3}$, \\ Andrius Stasiulis ${ }^{4}$ \\ ${ }^{1}$ Klaipèdos universitetine ligonine, Traumatologijos skyrius, \\ ${ }^{2}$ Lietuvos sveikatos mokslu universiteto Kauno klinikos, Ortropedijos-traumatologijos klinika, \\ ${ }^{3}$ Kauno klinikinè ligonine, Traumatologijos skyrius, \\ ${ }^{4}$ Klaipedos universiteto Reabilitacijos katedra
}

Raktažodžiai: klubo sąnario endoprotezavimas, cementinis implantas, mechaninis tvirtinimas, išlikimo dažnis, revizinè operacija.

\begin{abstract}
Santrauka
Kasmet Lietuvoje atliekama apie 4000 klubo sąnario endoprotezavimo operacijų. Tai yra vienas iš pagrindinių klubo sąnario osteoartrozès gydymo metodų. Lietuvoje 2011 metais įkurtas endoprotezavimo registras, kurio veikla nukreipta vertinti endoprotezavimo operacijų rezultatus bei pakartrotiniu endoprotezavimų priežastis. Šio darbo tikslas buvo ivvertinti naudojamų klubo sąnario implantų pasiskirstymą bei išlikimą tarp skirtingo amžiaus pacientų grupių. I tyrimą įtraukti visi LSER registruoti pirminiai klubo sąnario endoprotezavimo atvejai nuo $2011 \mathrm{~m}$. sausio $1 \mathrm{~d}$. iki $2013 \mathrm{~m}$. gruodžio 31 d. Pacientų sekimo periodas prasidedavo po atliktos operacijos ir tęsdavosi iki paciento mirties arba stebejjimo periodo pabaigos (2014 metu gruodžio 31 diena). Taip pat registruotos pakartotinès endoprotezavimo operacijos(revizijos) bei jų data. Tyrimo duomenimis, 2011-2013 metais atlikta iš viso 8850 klubo sąnario endoprotezavimo operacijų. Bendras implantų išlikimas praejjus vidutiniškai 30 mèn. po pirminès operacijos siekè 97,3 proc. Reikšmingo skirtumo tarp mechaninio ir cementinio tvirtinimo implantų išlikimo pacientams vyresniems kaip 60 metų ir pacientams iki 60 metų nenustatyta.
\end{abstract}

\section{Ivadas}

Klubo sąnario osteoartrozė yra vienas iš dažniausiai pa- sitaikančių ortopedinių ligų. Dažnai konservatyviai gydant šią patologiją geri rezultatai nepasiekiami, todèl siekiant pacientų lūkesčių pateisinimo, neretai atliekamos klubo sąnario endoprotezavimo operacijos. Lietuvoje kasmet atliekama apie 4000 klubo sąnario endoprotezavimo operacijų, kaip ir visame pasaulyje, kiekvienais metais sąnarių endoprotezavimo operacijų poreikis dideja (1-4). Tam turi ịtakos senstanti visuomenè bei didejjantis žmonių, sergančių lètinèmis degeneracinèmis sąnarių ligomis, skaičius (5-7).

Lietuvoje šiuo metu pirminiam klubo sąnario endoprotezavimui atlikti naudojami cementiniai, becementiniai bei mišraus fiksavimo tipo endoprotezai, kurių pasirinkimas dažnai priklauso nuo paciento amžiaus, fizinès būklès, operacijos apimties bei chirurgo patirties.

Siekiant ịvertinti ankstyvuosius ir atokiuosius operacinio gydymo rezultatus, daugumoje Europos Sajungos šalių veikia nacionaliniai endoprotezavimo registrai (8). 2011 metais ịkurtas Lietuvos sąnarių endoprotezavimo registras(LSER)(9). Nuo to laiko pradèti rinkti duomenys apie visose Lietuvos gydymo įstaigose atliktas kelio ir klubo sąnarių endoprotezavimo operacijas.

Klubo sąnarių endoprotezavimo operacijų rezultatų analizè suteikia galimybę įvertinti bei palyginti mūsų pacientų gydymo rezultatus tiek nacionaliniu, tiek tarptautiniu mastu. Pakartotinių endoprotezavimo operacijų priežasčių vertinimas ir atsirandantis grịžtamasis ryšys gydytojams, atliekantiems šias operacijas, suteikia galimybę pagerinti operacijų kokybę bei taikyti pacientams šiuolaikišką, moksliniais tyrimais pagrịstą gydymą.

Darbo tikslas: ịvertinti Lietuvoje atliekamas klubo sąnario endoprotezavimo operacijas bei naudojamų implantų pasiskirstymą pagal fiksacijos kaule principą tarp skirtingo 
amžiaus pacientų grupių.

\section{Darbo objektas ir metodika}

I tyrimą buvo įtraukti visi LSER duomenų bazèje užregistruoti pirminiai klubo sąnario endoprotezavimo atvejai nuo $2011 \mathrm{~m}$. sausio $1 \mathrm{~d}$. iki $2013 \mathrm{~m}$. gruodžio $31 \mathrm{~d}$. Itraukti pacientai stebèti iki $2014 \mathrm{~m}$. gruodžio 31 dienos. Tyrime dalyvavo 24 Lietuvos gydymo įstaigos, kuriose atliekamos šios operacijos. Visų tyrime dalyvaujančių ligoninių gydytojai ortopedai traumatologai po atliktos operacijos pildė elektroninę operacijos duomenų registracijos formą(10,11). Kiekvienos ligoninès gydytojai prisijungti prie šios duomenų bazès bei užpildyti elektroninę operacijos registracijos formą galèjo naudodamiesi įstaigai suteiktu vartotojo vardu ir slaptažodžiu. Gydytojų ir gydymo įstai-

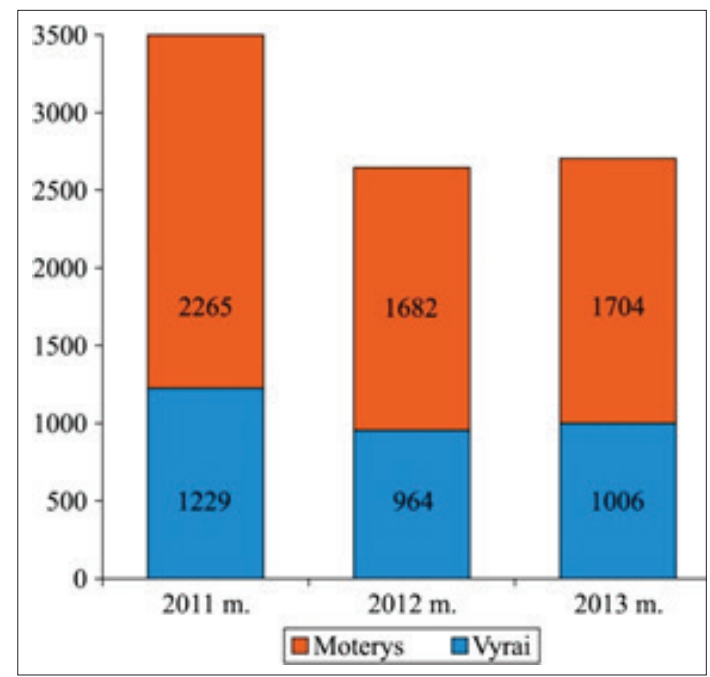

1 pav. Pacientų pasiskirstymas pagal lytị

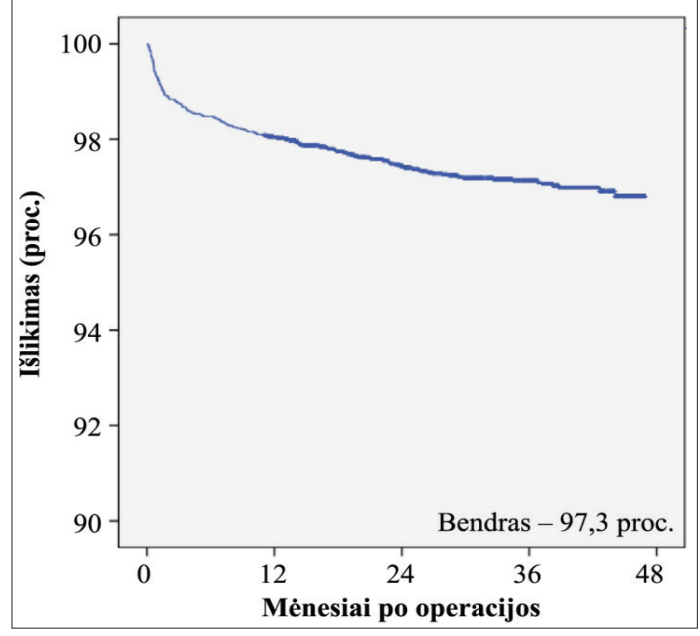

2 pav. Kaplan-Meier klubo sąnarių EP išlikimo kreivè gų dalyvavimas buvo neprivalomas, t.y. pagrịstas savanoriškumo/geranoriškumo principu. Pacientų identifikavimui naudotas unikalus identifikacijos numeris (asmens kodas). Asmens kodo naudojimas vèliau leido nesunkiai nustatyti, kuriems pacientams atliktos pakartotinès operacijos(12).

Registruoti pacientu demografiniai duomenys bei implantu fiksacijos kaule principas.

Taip pat registruotos pakartotinès endoprotezavimo operacijos(revizijos) bei jų data. Revizija apibrèžta kaip pakartotinè to paties sąnario operacija, kurios metu buvo pakeistas, pridètas arba pašalintas bent vienas iš EP komponentu.

Pagrindiniu vertinimo kriterijumi buvo implantų išlikimo dažnis po pirminès klubo sąnario endoprotezavimo operacijos. Pacientų sekimo periodas prasideddavo po atliktos operacijos ir trukdavo iki paciento mirties arba stebeji-

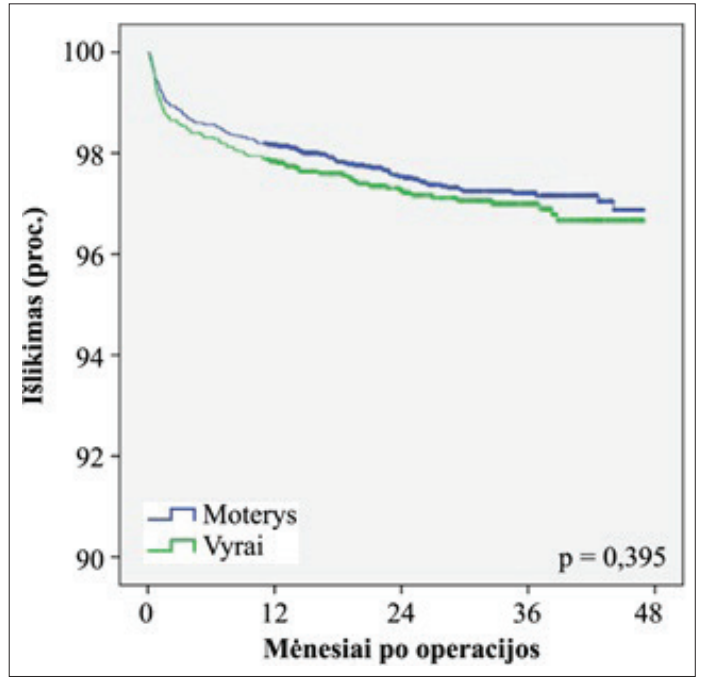

3 pav. Vyrų ir moterų klubo sąnarių EP išlikimo rezultatų palyginimas

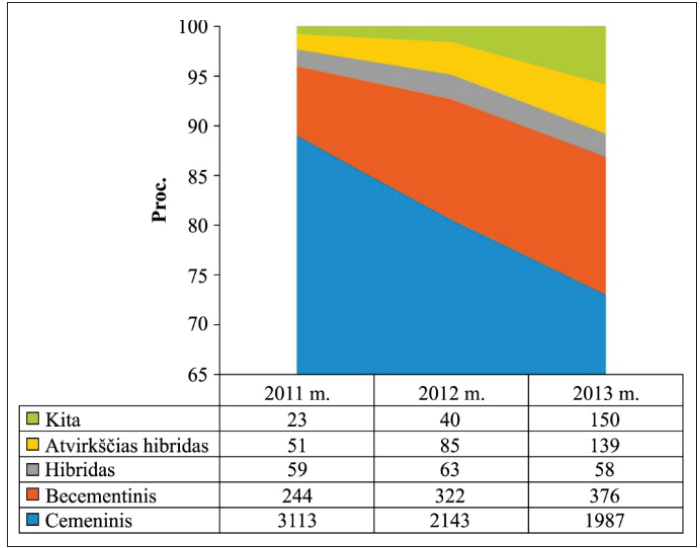

4 pav. EP pasiskirstymas pagal fiksacijos principą 


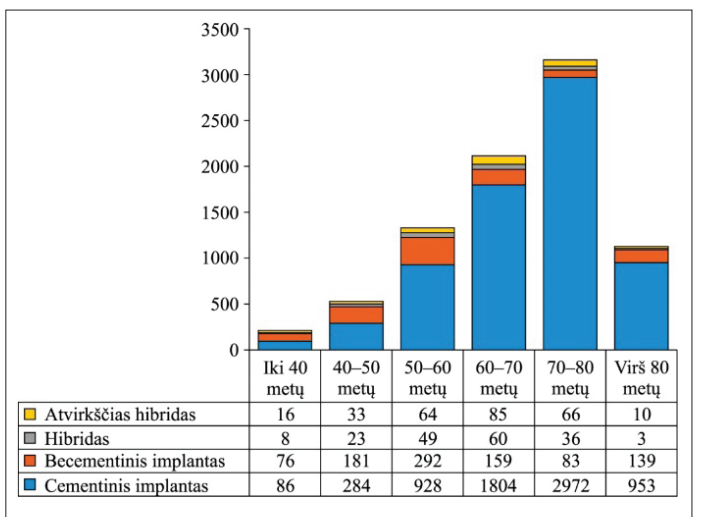

5 pav. Implantų išlikimas lyginant cementinius mechaniškai ir mišriai tvirtinamus implantus (visos diagnozès)

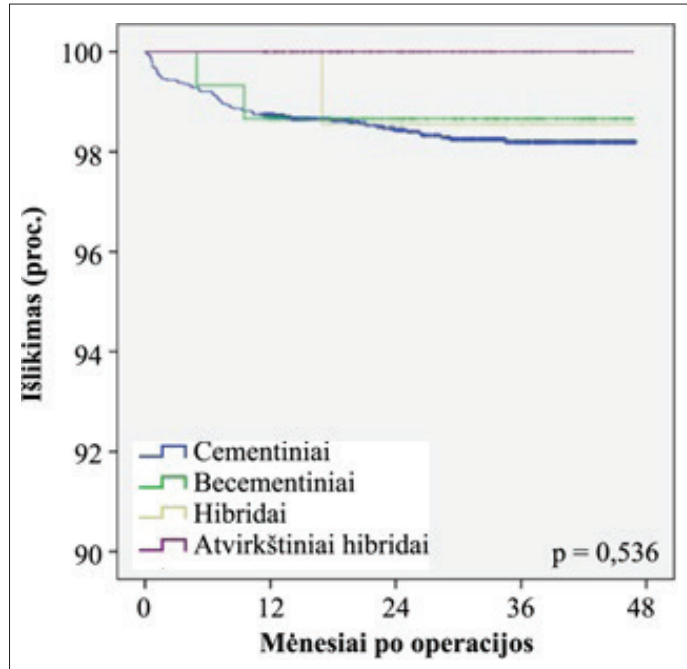

6 pav. Implantų pasiskirstymas pagal fiksacijos principą tarp atskirų amžiaus grupių

mo periodo pabaigos (2014 metų gruodžio 31 diena). Pacientai, kurie iki minèto periodo nebuvo dar kartą operuoti, buvo laikomi sèkmingais atvejais, t. y. su funkcionuojančiais endoprotezuotais sąnariais. O tie pacientai, kuriems buvo atliktos protezuoto sąnario pakartotinès operacijos, buvo laikomi nesėkmingais atvejais, revizijos datą laikant stebejjimo periodo pabaiga.

Sąnarių endoprotezavimo operacijų duomenų aprašomajai statistikai naudoti vidurkiai, medianos bei pasikliautiniai intervalai (PI). EP išlikimo kreivèms ịvertinti naudotas Kaplan-Meier metodas. Išlikimo kreivių palyginimui buvo taikytas Log-rank testas. Skirtumas buvo laikomas statistiškai reikšmingu, kai $p<0,05$. Duomenų analizè buvo atlikta naudojantis SPSS ir STATA programiniu paketu.

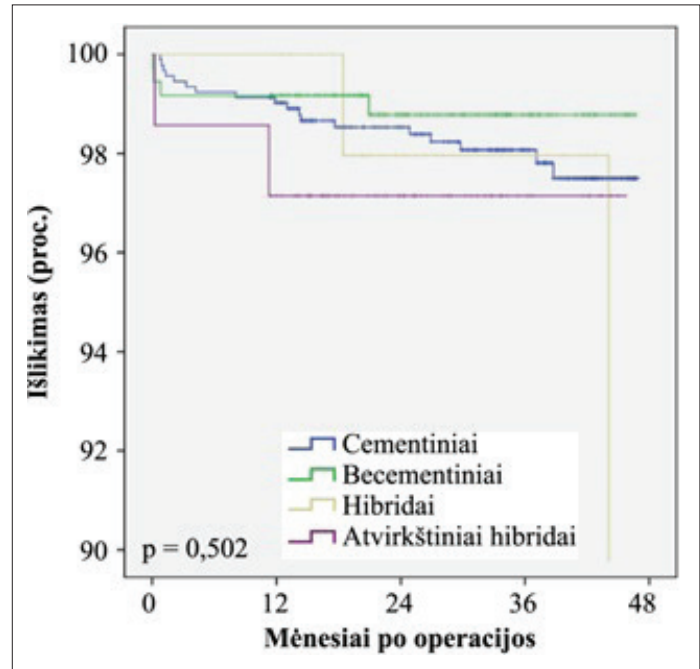

7 pav. Implantų išlikimas lyginant cementinius, mechaniškai ir mišriai tvirtinamus implantus pacientams virš 60 metur

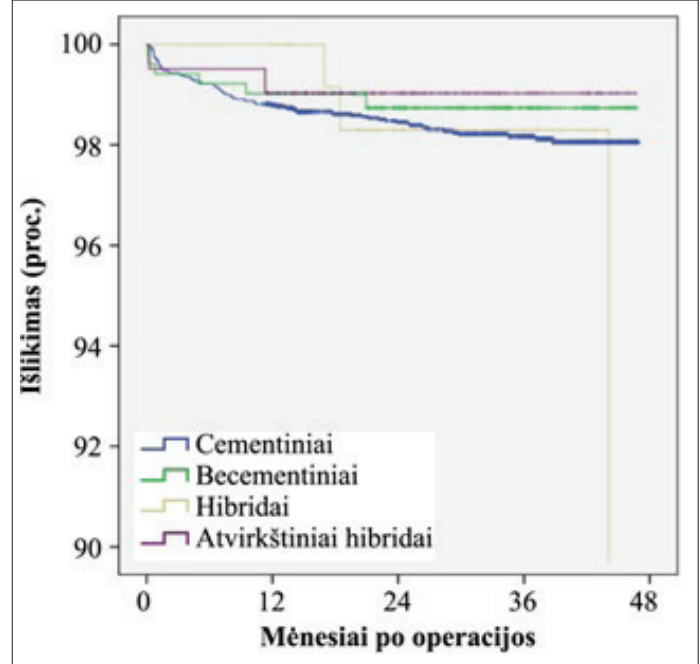

8 pav. Implantų išlikimas lyginant cementinius, mechaniškai ir mišriai tvirtinamus implantus pacientams iki 60 metų

Šiam moksliniam tyrimui išduotas bioetikos leidimas $\mathrm{Nr}$. BE-2-17.

\section{Rezultatai}

Tyrimo duomenimis, 2011-2013 metais klubo sąnario keitimo operacija atlikta 5651 moteriai ir 3199 vyrams, iš viso 8850 operacijų. Pacientų pasiskirstymas pagal lytị kiekvienais metais pateiktas 1 pav.

Bendras implantu išlikimas praejjus vidutiniškai 30 mèn. po pirminès operacijos siekè 97,3 proc. (2 pav.). Paly- 
ginus abiejų lyčių pacientų klubo sąnario endoprotezavimo duomenis, nustatyta, kad moteriškosios lyties pacientų endoprotezavimo rezultatai šiek tiek geresni, tačiau skirtumas nèra statistiškai reikšmingas ( $\mathrm{p}=0,395)$ ( 3 pav.).

2011-2013 metais Lietuvoje cementinio tvirtinimo klubo sąnario EP sudare 82 proc. visų atliktų endoprotezavimo operacijų. Likusiems pacientams implantuoti mechaninio arba mišraus tvirtinimo implantai. Vertinant klubo sąnario endoprotezavimo operacijų pasiskirstymą pagal klubo sąnario endoprotezo fiksacijos koncepciją nustatyta, kad 2012 metais, palyginti su 2011 metais, sumažejjo cementu tvirtinamų endoprotezų proporcija ir kartu didejjo mechaniškai tvirtinamų implantų panaudojimas. Mechaninio tvirtinimo endoprotezu skaičius augo ir 2013 metais. Klubo sąnario endoprotezu tipų pagal fiksacijos principą pasiskirstymas 2011-2013 metais pateiktas 4 paveiksle. Atlikę palyginamają implantų išlikimo pagal fiksacijos principą analizę, nenustatème statistiškai reikšmingo implantų išlikimo skirtumo tarp cementinio ir mechaninio tvirtinimo $\mathrm{EP}(5$ pav.).

LSER duomenų analizé, vertinanti 2011-2013 metu klubo sąnarių endoprotezų pasiskirstymą pagal fiksacijos principą skirtingose amžiaus grupèse, parodè, kad jaunesnio amžiaus pacientų grupèse stebimas didesnis mechaninio tvirtinimo implantų panaudojimas nei vyresnio amžiaus grupèse. Dažniausiai šio tipo implantai buvo naudoti 40-50 metų amžiaus grupèje -41 proc. Tačiau pastebèta, jog pacientų, vyresnių nei 80 metų amžiaus grupejje, mechaninio tvirtinimo implantai panaudoti net 13 proc. atvejų, lyginant su jaunesnių pacientų - 70-80 metų grupe, kurioje mechaninio tvirtinimo implantai naudoti tik 3 proc. pacientų (6 pav.).

Atlikus palyginamają analizę, lyginant implantų išlikimo rezultatus tarp dviejų amžiaus grupių, suskirstę juos pagal fiksacijos principą, reikšmingo skirtumo tarp mechaninio ir cementinio tvirtinimo implantų išlikimo pacientams vyresniems kaip 60 metu $(\mathrm{p}=0,536)(7 \mathrm{pav}$.$) ir pacientams$ iki 60 metų $(\mathrm{p}=0,502)$ ( 8 pav.) nenustatyta.

\section{Diskusija}

Remiantis kitu šaliu endoprotezavimo registru duomenimis, mechaninio tvirtinimo implantai, naudojami jauniems pacientams, susiję su geresniais išlikimo rezultatais. Švedų nacionalinio klubo sąnario registro duomenimis, 65 metų ir jaunesni pacientų amžius tai riba, kada turètų būti implantuojamas mechaninio tvirtinimo endoprotezas, kadangi tai susiję su ilgesniu implanto tarnavimo laiku (13). Anglijos ir Velso sąnarių endoprotezavimo registras nustato 60 metų kritinę ribą, kuri turètų nulemti implanto fiksacijos principo pasirinkimą (14). Siekdami įvertinti Lietuvos pacientus, mes pasirinkome 60 metų ribą ir paly- ginome endoprotezų išlikimo rezultatus dviejose amžiaus grupèse, suskirstę juos pagal fiksacijos principą. Atlikę palyginamają analizę, reikšmingo skirtumo tarp skirtingo tvirtinimo implantų išlikimo pacientams vyresniems kaip 60 metų ir pacientams iki 60 metų nenustatyta. Šie radiniai yra dèsningi, kadangi, remdamiesi kitų šalių endoprotezavimo registru patirtimi, turime pabrèžti, kad ankstyvasis endoprotezavimo rezultatų vertinimas dažniausiai neatspindi implantuojamų endoprotezų kokybès dèl sąlyginai trumpo stebėsenos laikotarpio. Šio laikotarpio duomenys leidžia nustatyti naudojamos operavimo technikos reikšmę ankstyvosioms komplikacijoms, komplikacijų dažnį bei šių operacijų atlikimo kokybę šalyje (15).

Pagal esamą VLK sąnarių endoprotezų pirkimo tvarką, Lietuvoje centralizuotai įsigyjami tik cementinio tvirtinimo implantai. Esant indikacijoms implantuoti mechaniškai tvirtinamus endoprotezus, implantus įsigyja patys pacientai. Mechaninio ir mišraus tvirtinimo implantai Lietuvoje sudare 18 proc. visų atliekamų klubo endoprotezavimo operacijų. Galima teigti, kad Lietuvoje mechaninio tvirtinimo implantų naudojimas nèra pakankamai grịstas medicininemis indikacijomis, kadangi VLK nefinansuoja šiu implantų ịsigijimo. Šių implantų naudojimas yra tiesiogiai susijęs su pacientų finansinèmis galimybėmis, kas sudaro tam tikras prielaidas gydymo paslaugų netolygumui, kadangi dalis pacientu, kuriems mechaninio tvirtinimo endoprotezai būtų indikuotini, neturi galimybių jų ịsigyti.

\section{Išvados}

1. Lietuvoje atliekamos pakartotinès klubo endoprotezavimo operacijos sudaro 2,7 proc. ir paciento lytis ankstyvuoju stebejjimo laikotarpiu implantų išlikimo rezultatams itakos neturi.

2. Endoprotezavimo metu naudojamų implantų fiksacijos principas neveikia bendro implanto išlikimo dažnio kaip ir visoje populiacijoje, taip ir lyginant išlikimo dažni tarp skirtingų amžiaus grupių.

\section{Literatūra}

1. Wells VM, Hearn TC, McCaul KA, Anderton SM, Wigg AE, Graves SE. Changing incidence of primary total hip arthroplasty and total knee arthroplasty for primary osteoarthritis. The Journal of arthroplasty 2002;17(3):267-73.

https://doi.org/10.1054/arth.2002.30414

2. Malchau H, Herberts P, Eisler T, Garellick G, Soderman P. The Swedish total hip replacement register. The Journal of bone and joint surgery American volume. 2002;84-A Suppl 2:2-20. https://doi.org/10.2106/00004623-200200002-00002

3. Robertsson O, Dunbar MJ, Knutson K, Lidgren L. Past incidence and future demand for knee arthroplasty in Sweden: a report 
from the Swedish knee arthroplasty register regarding the effect of past and future population changes on the number of arthroplasties performed. Acta orthopaedica Scandinavica 2000;71(4):376-80.

https://doi.org/10.1080/000164700317393376

4. Birrell F, Johnell O, Silman A. Projecting the need for hip replacement over the next three decades: influence of changing demography and threshold for surgery. Annals of the Rheumatic Diseases 1999;58(9):569-72.

https://doi.org/10.1136/ard.58.9.569

5. Bijlsma JW, Berenbaum F, Lafeber FP. Osteoarthritis: an update with relevance for clinical practice. Lancet (London, England). 2011;377(9783):2115-26.

https://doi.org/10.1016/S0140-6736(11)60243-2

6. Dieppe PA, Cushnaghan J, Shepstone L. The Bristol 'OA500' study: progression of osteoarthritis (OA) over 3 years and the relationship between clinical and radiographic changes at the knee joint. Osteoarthritis and cartilage / OARS, Osteoarthritis Research Society 1997;5(2):87-97. https://doi.org/10.1016/S1063-4584(97)80002-7

7. Goldring MB. The role of the chondrocyte in osteoarthritis. Arthritis and rheumatism 2000;43(9):1916-26.

https://doi.org/10.1002/1529-0131(200009)43:9<1916::AIDANR2>3.0.CO;2-I

8. von Knoch F, Marchie A, Malchau H. Total joint registries: a foundation for evidence-based arthroplasty. The virtual mentor : VM 2010;12(2):124-9.

https://doi.org/10.1001/virtualmentor.2010.12.2.oped1-1002

9. Tarasevicius S, Cebatorius A, Valaviciene R, Stucinskas J, Leonas L, Robertsson O. First outcome results after total knee and hip replacement from the Lithuanian arthroplasty register. Medicina (Kaunas, Lithuania) 2014;50(2):87-91.

https://doi.org/10.1016/j.medici.2014.06.004

10. Registras LSE. Klubo sąnario operacijos registracijos forma 2015 [cited 201511 13]. Available from: https://registras.lsed. lt/index.php/klubo_irasas/new.

11. Registras LSE. Kelio sąnario operacijos registracijos forma 2015 [cited 201511 13]. Available from: https://registras.lsed. lt/index.php/kelio_irasas/new.

12. Kolling C, Simmen BR, Labek G, Goldhahn J. Key factors for a successful National Arthroplasty Register. The Journal of bone and joint surgery British volume 2007;89(12):1567-73.
https://doi.org/10.1302/0301-620X.89B12.19409

13. Ahnfelt L, Herberts P, Malchau H, Andersson GB. Prognosis of total hip replacement. A Swedish multicenter study of 4,664 revisions. Acta orthopaedica Scandinavica Supplementum 1990;238:1-26.

14. Jameson SS, Mason J, Baker PN, Gregg PJ, Deehan DJ, Reed MR. Implant optimisation for primary hip replacement in patients over 60 years with osteoarthritis: a cohort study of clinical outcomes and implant costs using data from England and Wales. PloS one 2015;10(11):e0140309.

https://doi.org/10.1371/journal.pone.0140309

15. Herberts $P$, Malchau H. Long-term registration has improved the quality of hip replacement: a review of the Swedish THR Register comparing 160,000 cases. Acta orthopaedica Scandinavica 2000;71(2):111-21.

https://doi.org/10.1080/000164700317413067

\section{THE SURVIVAL RATE AND IMPLANT DISTRIBUTION, ACCORDING TO THE TYPE OF FIXATION USED IN TOTAL HIP ARTHROPLASTY, FOR PATIENTS OF DIFFERENT AGE GROUPS \\ A. Čebatorius, A. Lebedev, J. Stučinskas, D. Senkanec, A. Stasiulis}

Key words: total hipe artrhoplasty, cemented implant, mechanical fixation, survival rate, revisional surgery.

Summary

Every year about 4000 hip replacement surgeries are performed in Lithuania. It is a main method for the osteoarthritis treatment. In 2011 a Lithuanian register of arthroplasty was started aiming to analyse the results of the hip and knee replacement surgery as well as the revision rate of the least. The aim of this study was to evaluate the implants being used for the patients of different age groups as well as their survival rate. The study included all cases of primal hip arthroplasty starting from 2011 untill the 1st of January 2013. A follow up of 1 year was achieved. The revision surgeries were also recorded. According to the survey during a period from 2011 to 2013 there was a total of 8850 hip arthroplasties performed. The overall implant survival after an average of 30 months following the initial surgery was 97.3 percent. There was no significant difference between cemented and uncemented implants survival rate in patients aged over and under 60 years.

Correspondence to: a.cebatorius@gmail.com

Gauta 2017-01-05 